\title{
Branqueamento dentário e efeitos antibacterianos da casca de Juglans regia: um estudo preliminar.
}

Éber Coelho Paraguassu (1) e Thiago Coelho Guimarães (2).

\section{$\underline{\text { ARTIGO ORIGINAL }}$}

Resumo

Objetivos. Medicamentos naturais com efeitos antimicrobianos têm sido investigados nas últimas décadas. $\mathrm{O}$ objetivo deste estudo foi avaliar o clareamento dentário e os efeitos antimicrobianos do extrato etanólico da casca da noz persa "Juglans regia". Materiais $e$ métodos. A concentração inibitória mínima (MIC) foi determinada usando um ensaio de microdiluição em caldo que foi conduzido através de um método de diluição em série de 2 vezes, e um experimento de clareamento foi feito in vitro em dentes extraídos, com um teste de $\mathrm{pH}$ sendo realizado em diluições de 2 vezes do extrato de etanol. Resultado. Verificou-se que o MIC para Enterobacter e E. coli e Staphylococcus eVerificou-se que Pseudomonas era de $5 \mathrm{mg} / \mathrm{ml}$ e 2,5 $\mathrm{mg} / \mathrm{ml}$, respectivamente. Ambas as diluições foram consideradas ácidas, e o extrato da casca de Juglans regia também demonstrou a capacidade de clarear os dentes. Conclusão. Este estudo apóia o uso da casca de Juglans regia como um produto natural em odontologia devido à comprovada capacidade antimicrobiana, bem como seu efeito clareador. Relevância clínica . O extrato de erva pode ser incorporado aos tipos de creme dental comercialmente disponíveis para aumentar seus efeitos clareadores e antimicrobianos.

Palavras Chave: Clareamento dental, Branqueamento dental, Juglans regia, Produtos Naturais. 


\title{
Tooth whitening and antibacterial effects of Juglans regia bark: a preliminary study.
}

\begin{abstract}
Objectives: Natural medicines with antimicrobial effects have been investigated in recent decades. The aim of this study was to evaluate tooth whitening and the antimicrobial effects of the ethanolic extract of the Persian nutshell "Juglans regia". Materials and methods: The minimum inhibitory concentration (MIC) was determined using a broth microdilution assay that was conducted using a 2-fold serial dilution method, and a whitening experiment was done in vitro on extracted teeth, with a $\mathrm{pH}$ test being performed in 2-fold dilutions of the ethanol extract. Result. It was found that the MIC for Enterobacter and E. coli and Staphylococcus e It was found that Pseudomonas was $5 \mathrm{mg} / \mathrm{ml}$ and $2.5 \mathrm{mg} / \mathrm{ml}$, respectively. Both dilutions were considered acidic, and the bark extract of Juglans regia also demonstrated the ability to whiten teeth. Conclusion. This study supports the use of Juglans regia bark as a natural product in dentistry due to its proven antimicrobial capacity, as well as its whitening effect. Clinical relevance: The herb extract can be incorporated into the types of commercially available toothpaste to increase its whitening and antimicrobial effects.
\end{abstract}

Keywords: Tooth whitening, Tooth whitening, Juglans regia, Natural Products.

Instituição afiliada: 1- GOE/Uniavan. 2- Cirurgião Dentista e pesquisador independente.

Dados da publicação: Artigo recebido em 10 de Abril, revisado em 15 de Abril, aceito para publicação em 20 de Abril e publicado em 28 de Março.

DOI: https://doi.org/10.36557/2674-8169.2021v3n2p25-39

Éber Coelho Paraguassu paraguassutans@gmail.com

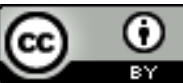

This work is licensed under a Creative Commons Attribution 4.0 International

License. 


\section{INTRODUÇÃO}

Com o aumento da incidência de doenças bucais e a demanda por dentes esteticamente agradáveis, é importante encontrar produtos de sucesso e econômicos que atendam a essas necessidades. Isso exige a importância de avaliar a eficácia das crenças de saúde bucal e práticas tradicionais que usam plantas medicinais. A saúde bucal é um estado de bem-estar funcional, estrutural, estético, fisiológico e psicossocial definido pela ADA e é essencial para a saúde geral e a qualidade de vida de um indivíduo [1].

$\mathrm{Na}$ boca humana, foram detectadas mais de 700 cepas bacterianas diferentes. Essas bactérias se acumulam nos tecidos orais duros e moles e podem ser encontradas em nichos de placa dentária [ 2 ]. Um equilíbrio complexo entre o hospedeiro, o meio ambiente e a microflora ocorre na saúde bucal. Isso se deve a bactérias comensais que são sugeridas como necessárias para manter a saúde bucal [3] A relação simbiótica entre a bactéria e o hospedeiro é interrompida durante a doença, resultando em um desequilíbrio na microbiota do residente oral, levando ao domínio de bactérias potencialmente patogênicas. Metabólitos nocivos, endotoxinas como lipopolissacarídeos, exotoxinas e ácido teicóico serão produzidos por bactérias que invadem as células hospedeiras. Essas bactérias alteram o ambiente, diminuindo o $\mathrm{pH}$, alterando a composição microbiana da placa dentária e estimulando a colonização de bactérias mais anaeróbias ou acidogênicas, resultando em sequelas desfavoráveis. Como consequência, existem cáries dentárias e doenças periodontais e muitas outras doenças bucais [4] Para minimizar a carga bacteriana na boca, é, portanto, necessário manter a higiene oral, portanto, a escovação com dentifrício fluoretado duas vezes ao dia e o uso do fio dental devem ser praticados.

Recomenda-se também o uso de produtos adjuvantes como enxaguatórios bucais e dentifrícios especiais de acordo com suas indicações. Uma das preocupações mais comuns com a estética dentária é a cor dos dentes. Ultimamente tem havido um grande interesse em obter dentes mais brancos. Os produtos de clareamento dentário podem ser classificados em duas categorias principais, que incluem agentes clareadores contendo peróxidos e dentifrícios. Os agentes clareadores podem ser usados em casa ou pelo dentista. Normalmente, eles estão associados à sensibilidade dentária e irritação moderada do tecido mole. Por outro lado, os dentifrícios operam por polimento, quelação química ou outras ações não branqueadoras, portanto, são considerados muito mais suaves, mas menos eficazes. Ambos os meios de clareamento requerem conformidade e são relativamente caros, e uma vez que a coloração ocorrerá inevitavelmente,

As plantas têm sido utilizadas para fins medicinais há várias décadas, com uma 
tendência aumentada para a automedicação, e ainda são muito utilizadas até hoje. Isso se deve principalmente aos efeitos colaterais de vários medicamentos sintéticos, ao surgimento de resistência a muitos medicamentos para doenças infecciosas e ao alto custo dos medicamentos. Essas plantas medicinais têm princípios ativos e podem ser usadas diretamente sem processamento industrial ou podem ser processadas para purificação e alteração, que podem então ser integradas em produtos medicinais. Algumas plantas apresentam potencial promissor, mas muitas delas permanecem não testadas. Juglans regia é uma dessas antigas plantas tradicionais, que é identificada com vários nomes em muitas partes do mundo, incluindo a nogueira persa, a nogueira comum, a nogueira inglesa, a nogueira dos Cárpatos e a noz da Madeira [ 5 ]. Em várias culturas, também possui várias palavras locais, como derum, dandasa e Sewak. Pelas vantagens que oferece para a saúde oral, a casca desta árvore tem sido tradicionalmente utilizada como galho para limpar os dentes. Isso envolve a limpeza da cavidade oral, o clareamento dos dentes, comumente feito no Norte da África, Sul da Ásia e Oriente Médio, além de prevenir a formação de cálculos e mau hálito. Essa planta não apenas servia para fins dentais, mas também era usada como um corante labial semelhante a batons para fins cosméticos [ 6 ].

Infelizmente, os estudos não comprovaram bem essas vantagens. Portanto, o objetivo deste estudo é avaliar a eficácia da casca de Juglans regia, especialmente em termos de clareamento in vitro, efeito antimicrobiano e nível de $\mathrm{pH}$. Devido ao seu custo mais baixo, ampla disponibilidade e facilidade de uso, pode ser usado como uma forma adjuvante para melhorar a manutenção regular da higiene oral e fornecer aprimoramento estético.

\section{MATERIAS E MÉTODOS}

Este estudo laboratorial in vitro foi conduzido no Instituto de Pesquisas Médicas de Sharjah (SIMR), Universidade de Sharjah, Sharjah, Emirados Árabes Unidos.

\section{Critério de inclusão}

(1) A casca do caule é originária exclusivamente do norte do Irã

(2) Dentes anteriores sãos sem mancha intrínseca

\section{Critério de exclusão}

(1) O caule late de uma fonte desconhecida

(2) Dentes com cárie extensa e / ou com coloração intrínseca

A coleta e extração da casca do caule foram feitas da seguinte forma.

\section{Coleta e gerenciamento de amostras de Juglans regia}


A casca do caule da Juglans regia foi coletada em um mercado local de Naif Souq, em Dubai, nos Emirados Árabes Unidos, e foi confirmado pelo fornecedor que a origem é do norte do Irã. A planta foi transformada em pó fino em uma carpintaria. O pó foi então pesado com um peso total de 820 gramas.

\section{Preparação do extrato de etanol}

O pó foi dividido em duas massas iguais e depositado uniformemente em dois grandes frascos. Em seguida, etanol 99\% foi adicionado até o pó estar completamente suspenso. Isso foi feito para garantir a saturação completa do etanol pelo pó. Para permitir que o pó se dissolva, a mistura foi agitada durante 10 minutos e deixada repousar durante 10 minutos. Isso resultou na separação da solução em 2 camadas: uma camada etanólica líquida e uma camada de pó não dissolvido precipitou no fundo do frasco. Usando um funil de Buchner, o líquido foi filtrado através de papel de filtro duplo e uma sucção a vácuo foi usada para isolar o líquido do pó não dissolvido. Este método foi realizado três vezes para cada um dos frascos. O líquido resultante foi então evaporado usando uma máquina de vapor rotativa para evaporar o etanol, que resultou em um extrato concentrado. $O$ extrato foi então armazenado em frascos e mantido aberto por alguns dias para permitir que mais etanol evaporasse. Para atingir uma concentração de $0,25 \mathrm{mg} / \mu \mathrm{l}$, o extracto foi dissolvido em DMSO (dimetilsulfóxido), um líquido orgânico altamente polar que é comumente utilizado como um solvente químico.

\section{Identificação de componentes de extração}

Conforme as amostras secaram, $50 \mu \mathrm{L}$ de agente de derivatização foram adicionados a cada amostra e deixados por cerca de 30 minutos. $150 \mu \mathrm{L}$ de solvente hexano foram posteriormente adicionados e misturados com a solução existente. A solução foi filtrada por filtro de seringa de PTFE de 0,22 $\mu \mathrm{m}$ e então transferida para frascos de GC, e eles estavam prontos para serem processados por GC-MS (cromatografia gasosa-espectrometria de massa) para identificação dos componentes do extrato. Os compostos individuais nos extrativos foram identificados por seu tempo de retenção em relação aos compostos conhecidos, conforme mostrado na Figura 1 .

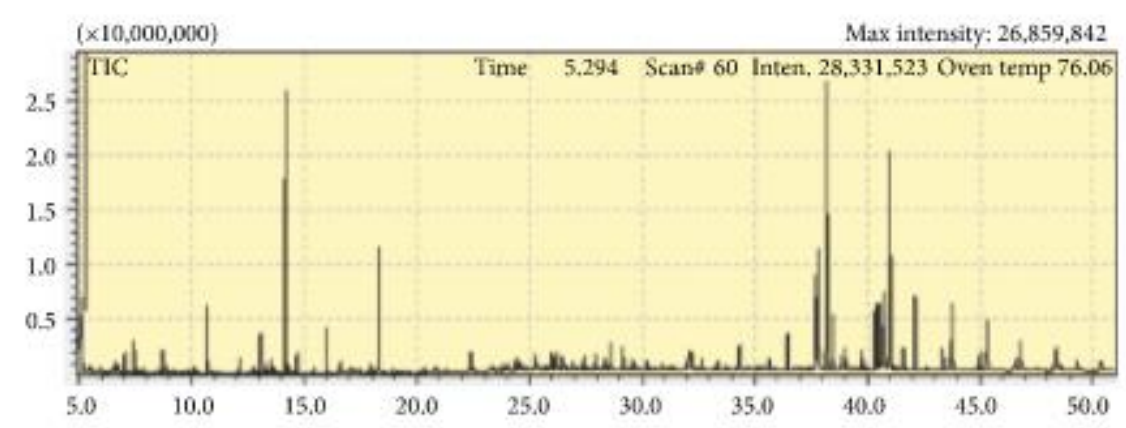

Figura 1: Análise por GC-MS do extrato de Juglans regia .

\section{Preparação de teste antimicrobiano}


A atividade antimicrobiana foi avaliada contra Staphylococcus gram-positivos, Escherichia coli gram-negativos, Pseudomonas e Enterobacteria . O método utilizado foi a diluição em série de 2 vezes com uma duplicata feita para cada bactéria e seus respectivos antibióticos em placas de 96 poços $(12 \times 8)$, iniciando na concentração de 5,0 $\mathrm{mg} / \mathrm{ml}$. Duas placas de poços contêm, cada uma, 2 amostras bacterianas, uma contendo Staphylococcus e Pseudomonas e a outra contendo E. coli e Enterobacter. O DMSO foi usado como um controle negativo para garantir que a inibição do crescimento bacteriano fosse devido ao ingrediente ativo no extrato e não ao DMSO. O antibiótico amicacina foi usado como controle positivo para E. coli e Pseudomonas, e o antibiótico Ciprofloxacina foi usado para Staphylococcus e Enterobacter . O controle positivo foi usado para garantir que houve inibição do crescimento, visto como falta de turbidez, e para comparar esses resultados com o efeito do extrato sobre as bactérias. O controle de crescimento consistindo de bactérias suspensas em caldo foi usado para garantir que o caldo tivesse valor nutricional para as bactérias e resultasse em crescimento. $O$ controle de mídia consistindo apenas em caldo foi usado para garantir a pureza do caldo.

Cada uma das bactérias incubadas foi suspensa em solução salina para atingir uma densidade óptica de 0,5 unidades de McFarland. $100 \mu$ I de cada bactéria suspenso foi adicionado a tubos de ensaio contendo $9,9 \mathrm{ml}$ de caldo para atingir um volume total de $10 \mathrm{ml}$ de caldo contendo as bactérias em suspensão.

Uma placa de 96 poços foi usada, cada placa de poço tem 12 colunas e 8 linhas (AH) como mostrado nas Tabelas 1 e 2 , e uma vez que cada placa foi usada para 2 bactérias, havia uma imagem de espelho em cada placa de poço. A concentração inicial foi de 5,0 mg / ml. Para alcançar esta concentração, $2 \mu$ I foi feita a partir do extracto $(0,25 \mathrm{mg} / \mu \mathrm{l})$, mas uma vez que é um 2 vezes a diluição em série, $4 \mu \mathrm{I}$ foi feita. A fim de alcançar um volume total de $100 \mu \mathrm{I}$ em A1 e B1, $96 \mu$ I de caldo contendo as bactérias em suspensão e de $4 \mu \mathrm{I}$ de extracto $(0,25 \mathrm{mg} / \mu \mathrm{l})$ foram adicionados para cada bactéria. $50 \mu 1$ de caldo contendo bactérias suspensas foi adicionado a todos os poços de A2 a A12 e de B2 a B12. Usando uma micropipeta, $50 \mu$ I de A1 foi transferida para o poço seguinte (A2), que já continha $50 \mu \mathrm{I}$ de caldo contendo bactérias em suspensão, resultando numa proporção de 1: diluição em série 2 , o que resultou num $\mathrm{mg} / \mathrm{ml}$ de concentração de 2,5. Este passo foi repetido transferência consecutivamente até A12, descartando-se $50 \mu$ la partir da última bem para acabar com o mesmo volume em todos os poços (50 $\mu \mathrm{l})$. Portanto, as concentrações da amostra foram $5.000 \mathrm{mg} / \mathrm{ml}, 2.500 \mathrm{mg} / \mathrm{ml}, 1.250 \mathrm{mg}$ / $\mathrm{ml}, 0,625 \mathrm{mg} / \mathrm{ml}$ e assim por diante. A duplicata que foi feita na linha B foi para eliminar erros experimentais. 
Tabela 1: Valores do leitor de microplaca para a placa de 96 poços contendo $E$. coli e Enterobacter e seus antibióticos complementares (Amikan e Ciprofloxacina).

\begin{tabular}{|c|c|c|c|c|c|c|c|c|c|c|c|c|c|}
\hline & & $\begin{array}{c}5,0 \mathrm{mg} / \\
\mathrm{mL}\end{array}$ & $\begin{array}{c}2,5 \mathrm{mg} / \\
\mathrm{ml}\end{array}$ & $\begin{array}{c}1,25 \mathrm{mg} / \\
\mathrm{mL}\end{array}$ & $\begin{array}{c}0,625 \mathrm{mg} / \\
\mathrm{mL}\end{array}$ & $\begin{array}{c}0,313 \mathrm{mg} / \\
\mathrm{mL}\end{array}$ & $\begin{array}{c}0,156 \mathrm{mg} / \\
\mathrm{mL}\end{array}$ & $\begin{array}{c}0,078 \mathrm{mg} / \\
\mathrm{mL}\end{array}$ & $\begin{array}{c}0,039 \mathrm{mg} / \\
\mathrm{mL}\end{array}$ & $\begin{array}{c}0,020 \mathrm{mg} / \\
\mathrm{mL}\end{array}$ & $\begin{array}{c}0,010 \mathrm{mg} / \\
\mathrm{mL}\end{array}$ & $\begin{array}{c}0,005 \mathrm{mg} / \\
\mathrm{mL}\end{array}$ & $\begin{array}{c}0,002 \mathrm{mg} / \\
\mathrm{mL}\end{array}$ \\
\hline & & 1 & 2 & 3 & 4 & 5 & 6 & 7 & 8 & 9 & 10 & 11 & 12 \\
\hline Estafilococo & UMA & 3.888 & 1.561 & 1.454 & 1.327 & 1.442 & 1.462 & 1.355 & 1.355 & 1.399 & 1,312 & 1.396 & 1.403 \\
\hline Estafilococo & B & 3,77 & 1.792 & 1.347 & 1,136 & 1.321 & 1.419 & 1.328 & 1,306 & 1.285 & 1,34 & 1.339 & 1.333 \\
\hline Ciprofloxacino & $\mathrm{C}$ & 0,132 & 0,16 & 0,238 & 1.328 & 1.356 & 1.354 & 1.349 & 1.342 & 1,348 & 1.366 & 1,345 & 0,208 \\
\hline Ciprofloxacino & $\mathrm{D}$ & 0,17 & 0,191 & 0,691 & 1,376 & 1,345 & 1.271 & 1,37 & 1,38 & 1.385 & 1.454 & 1.458 & 0,258 \\
\hline Amicacina & $\mathrm{E}$ & 0,12 & 0,161 & 0,200 & 0,674 & 0,657 & 0,722 & 0,752 & 0,742 & 0,677 & 0,758 & 0,77 & 0,232 \\
\hline Amicacina & $\mathrm{F}$ & 0,185 & 0,19 & 0,228 & 0,717 & 0,726 & 0,746 & 0,757 & 0,796 & 0,777 & 0,741 & 0,761 & 0,268 \\
\hline Pseudomonas & G & 3,513 & 1,62 & 0,582 & 0,87 & 0,734 & 0,717 & 0,862 & 0,856 & 0,759 & 0,776 & 0,852 & 1.043 \\
\hline Pseudomonas & $\mathrm{H}$ & 3.831 & 2,196 & 0,574 & 0,816 & 0,969 & 0,884 & 0,912 & 0,969 & 0,953 & 0,931 & 0,999 & 1.079 \\
\hline
\end{tabular}

Tabela 2: Valores do leitor de microplaca para a placa de 96 poços contendo Staphylococcus e Pseudomonas e seus antibióticos complementares (Amikan e

\begin{tabular}{|c|c|c|c|c|c|c|c|c|c|c|c|c|c|}
\hline & & $\begin{array}{c}5,0 \mathrm{mg} / \\
\mathrm{mL}\end{array}$ & $\begin{array}{c}2,5 \mathrm{mg} / \\
\mathrm{ml}\end{array}$ & $\begin{array}{c}\text { 1,25 mg / } \\
\mathrm{mL}\end{array}$ & $\begin{array}{c}0,625 \mathrm{mg} / \\
\mathrm{mL}\end{array}$ & $\begin{array}{c}0,313 \mathrm{mg} / \\
\mathrm{mL}\end{array}$ & $\begin{array}{c}0,156 \mathrm{mg} / \\
\mathrm{mL}\end{array}$ & $\begin{array}{c}0,078 \mathrm{mg} / \\
\mathrm{mL}\end{array}$ & $\begin{array}{c}0,039 \mathrm{mg} / \\
\mathrm{mL}\end{array}$ & $\begin{array}{c}0,020 \mathrm{mg} / \\
\mathrm{mL}\end{array}$ & $\begin{array}{c}0,010 \mathrm{mg} / \\
\mathrm{mL}\end{array}$ & $\begin{array}{c}0,005 \mathrm{mg} / \\
\mathrm{mL}\end{array}$ & $\begin{array}{c}0,002 \mathrm{mg} / \\
\mathrm{mL}\end{array}$ \\
\hline & & 1 & 2 & 3 & 4 & 5 & 6 & 7 & 8 & 9 & 10 & 11 & 12 \\
\hline E. Coli & UMA & 4.077 & 2.394 & 1.616 & 1,31 & 1,21 & 1.083 & 1.064 & 1.049 & 1.073 & 0,953 & 1.026 & 1,119 \\
\hline E. Coli & B & 3,909 & 2,367 & 1.604 & 1.298 & 1.044 & 0,988 & 1.038 & 0,98 & 0,984 & 0,837 & 1.074 & 1.093 \\
\hline Amicacina & $\mathrm{C}$ & 0,278 & 0,579 & 0,915 & 0,961 & 0,999 & 0,914 & 1.016 & 0,946 & 0,971 & 1.018 & 1.053 & 0,362 \\
\hline Amicacina & D & 0,325 & 0,601 & 0,858 & 0,947 & 1.015 & 0,923 & 0,966 & 0,996 & 0,944 & 0,972 & 1.033 & 0,408 \\
\hline Ciprofloxacino & $\mathrm{E}$ & 0,694 & 0,845 & 1.205 & 1.222 & 1,31 & 1.301 & 1.253 & 1.241 & 1,307 & 1.549 & 1.322 & 0,225 \\
\hline Ciprofloxacino & $\mathrm{F}$ & 0,191 & 0,966 & 1.226 & 1.191 & 1,23 & 1.154 & 1,153 & 1,11 & 1.051 & 1.456 & 1.212 & 0,261 \\
\hline Enterobacter & G & 3.887 & 2,38 & 1.408 & 1.075 & 1.04 & 1.258 & 1,122 & 1,101 & 1.06 & 1.172 & 1.171 & 1,183 \\
\hline Enterobacter & $\mathrm{H}$ & 3.868 & 2.231 & 1.384 & 1.084 & 1.066 & 1.236 & 1.056 & 1.096 & 1.086 & 1.073 & 1.091 & 1.06 \\
\hline
\end{tabular}
Ciprofloxacina).

Para poços C1and D1, um controlo positivo consiste em $5 \mu$ I do antibiótico cortesia com $95 \mu \mathrm{I}$ de caldo contendo as bactérias em suspensão. $50 \mu \mathrm{I}$ de caldo contendo bactérias em suspensão foi adicionada a todos os poços de C2 a C9 e D2 para D9. $50 \mu$ I foi feita a partir de C1 e transferida para o poço seguinte (C2), que já continha $50 \mu \mathrm{I}$ de caldo contendo as bactérias em suspensão. Este passo foi repetido transferência consecutivamente até $\mathrm{C} 9$, descartando-se $50 \mu \mathrm{I}$ a partir da última bem para acabar com o mesmo volume em todos os poços. Uma duplicata foi feita na linha D.

Outros controlos incluem o controlo negativo que consiste em $2 \mu \mathrm{I}$ de DMSO em $48 \mu \mathrm{I}$ de caldo contendo suspenso bactérias em C10 e D10, controlo de crescimento consistindo de $50 \mu$ I de caldo e $50 \mu$ I de bactérias suspensas em solução salina em C11 e D11, e meios de controle que consiste em $100 \mu$ I de caldo em C12 e D12. Todo o procedimento foi feito na outra metade da mesma placa de poço para as outras bactérias, bem como na segunda placa de poço para as outras duas bactérias. As placas de poços foram incubadas durante 24 horas a $37^{\circ} \mathrm{C}$ graus e foram então avaliadas visualmente quanto à turbidez e transportadas para um leitor de microplacas e digitalizadas. O leitor 
de microplaca mede a densidade óptica que fornece valores correlacionados com o crescimento bacteriano.

Devido à cor intensa de Juglans regia , a turbidez não pôde ser avaliada para as três primeiras concentrações que foram testadas contra cada bactéria; portanto, a análise de subcultura foi feita para confirmar a presença ou ausência de crescimento bacteriano

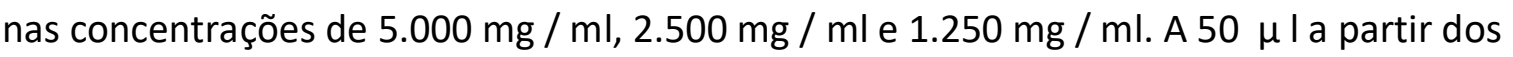
poços seleccionados foi transferido para placas de agar e deixadas a incubar durante mais 24 horas. As placas foram então analisadas.

\section{Preparação do experimento de clareamento}

Trinta dentes anteriores humanos hígidos de vários tons com camada de esmalte intacta e sem coloração intrínseca foram coletados da clínica de cirurgia oral no University Dental Hospital Sharjah e foram armazenados em solução salina após a extração para este estudo. Quinze dentes foram selecionados aleatoriamente para serem escovados com o extrato, e quinze foram selecionados como controle. Oito dentes foram escovados com soro fisiológico, e os sete restantes foram armazenados apenas em soro fisiológico sem escovagem. Todos os dentes foram corados artificialmente por imersão em uma solução de chá preparada pela dissolução de 5 saquinhos de chá, de 20 gramas cada, em $175 \mathrm{ml}$ de água a $60^{\circ} \mathrm{C}$. $\mathrm{O}$ chá foi deixado esfriar e os dentes foram imersos por 12 horas. Uma tonalidade de linha de base foi capturada usando Vita EasyShade ${ }^{\circledR}$ Advance 4.0. Uma solução foi feita usando o resultado antimicrobiano de MIC (5 mg / ml), dissolvendo $1 \mathrm{~g}$ deExtrato de Juglans regia em $2 \mathrm{ml}$ de DMSO e $198 \mathrm{ml}$ de solução salina. Os quinze casos selecionados foram escovados com escova manual por 2 minutos, na concentração de 5 $\mathrm{mg} / \mathrm{ml}$ da solução preparada. Os dentes foram então armazenados em solução salina entre cada exposição ao extrato. Oito dos dentes de controle foram escovados por 2 minutos com solução salina e armazenados novamente em solução salina para confirmar que o clareamento foi devido ao ingrediente ativo na planta Juglans régia e não devido à escovação. Os outros sete dentes não foram tocados e mantidos armazenados em solução salina, para garantir que não houvesse mudança de cor devido ao armazenamento em solução salina ou coloração retardada da solução de chá. Este processo foi repetido duas vezes ao dia durante 7 dias. Os dentes foram armazenados em solução salina entre as exposições à Juglans regiasolução para a duração da experiência. Uma segunda leitura foi feita no oitavo dia com Vita EasyShade ${ }^{\circledR}$ Advance 4.0 e anotada. Uma análise de comparação nas mudanças de tonalidade foi conduzida usando teste $t$ pareado .

\section{Preparação de teste de pH}

Um medidor de $\mathrm{pH}$ foi usado para medir o pH de diferentes diluições do extrato. Uma diluição em série de 2 vezes usando solução salina foi feita no extrato de concentração $5 \mathrm{mg} / \mathrm{ml}$ : o MIC. Em cada tubo de ensaio foram colocados $5 \mathrm{ml}$ de soro fisiológico, com exceção do primeiro, que continha apenas $10 \mathrm{ml}$ da solução do extrato. 5 
$\mathrm{ml}$ de cada tubo de ensaio foram transferidos para o próximo, resultando em diluição 1: 2. Cada tubo de ensaio foi bem misturado. A solução salina foi usada como controle para verificar a precisão do eletrodo do medidor de $\mathrm{pH}$. Seguindo as instruções do fabricante, o eletrodo foi enxaguado com água destilada e seco com tecido macio para remover o líquido do eletrodo antes de iniciar o experimento. O eletrodo foi inserido no primeiro tubo de ensaio ( $5 \mathrm{mg} / \mathrm{ml}$ ), e o resultado foi anotado. O eletrodo foi lavado com água destilada entre cada leitura para evitar contaminação e garantir a exatidão e precisão das leituras. Os mesmos passos foram seguidos para os outros 3 tubos de ensaio, e suas leituras foram anotadas.

\section{RESULTADOS}

\section{Os constituintes extrativos de Juglans regia}

Vinte ácidos graxos, três esteróis, seis ácidos orgânicos, ácidos minerais e um antibiótico foram identificados no extrato com a presença de nove compostos contendo álcool e 3 compostos fenólicos com oito açúcares como visto nas Tabelas 3 e 4.

Tabela 3: Ácidos graxos identificados em Juglans regia .

\begin{tabular}{lc}
\hline Ácido graxo & Tempo de retençăo \\
\hline Ácido 4-metilvalérico & 9,621 \\
Ácido 4-hidroxibutanoico & 12,766 \\
Ácido 17-octadecnóico & 14,298 \\
Ácido butanodioico & 14,345 \\
Ácido nonanoico & 15,299 \\
Ácido mirístico & 25.368 \\
Ácido 10,13-octadecadienóico, éster metílico & 30,06 \\
Éster etílico de ácido linoléico & 31,251 \\
Ácido pentacontanóico, éster etílico & 31.859 \\
Ácido 9,12-octadecadienóico & 32,103 \\
Ácido 13-octadecenóico & 32,33 \\
11-metiltricosano & 32.611 \\
Ácido esteárico, derivado de TMS & 32.678 \\
Palmitato de 2-hidroxietil & 34,142
\end{tabular}

Tabela 4: Esteróis identificados em Juglans regia. 


\begin{tabular}{lc}
\hline Sterol & Tempo de retenção \\
\hline Campesterol & 47,187 \\
Estigmasterol & 47,52 \\
\hline Ácido orgânico & \\
\multicolumn{1}{c}{ Ácido lático } & 8,898 \\
Ácido etanimídico & 9,865 \\
Ácido glicólico & 10,68 \\
Ácido Cítrico & 24,722 \\
\hline
\end{tabular}

\section{Resultados do teste antimicrobiano}

Após a incubação das duas placas de 96 poços, a ausência de turvação foi primeiro avaliada visualmente. Os poços contendo concentração de 5,0 $\mathrm{mg} / \mathrm{ml}$ do extrato e as duas diluições seguintes eram todos de cor escura. Cor mais clara e turvação aparente foram observadas com o restante dos poços contendo uma concentração decrescente do extrato, o controle negativo e o controle de crescimento, indicando crescimento bacteriano. A ausência de turbidez foi observada com as três maiores concentrações do controle positivo e do controle de meio, indicando a ausência de bactérias.

Um leitor de microplaca foi usado para medir a densidade óptica em $570 \mathrm{~nm}$. Quanto menor for o valor dado, maior será a transmissão da luz e menor será a absorbância, indicando um baixo número de bactérias, e vice-versa, conforme mostrado nas Tabelas 1 e 2 . Todos os poços contendo $5,0 \mathrm{mg} / \mathrm{ml}$ para todas as bactérias deram um valor de densidade óptica de 4, que é arredondado para o número inteiro mais próximo. Os poços contendo $2,5 \mathrm{mg} / \mathrm{ml}$ de extrato deram um valor de densidade óptica de 2 , que é arredondado para o número inteiro mais próximo para todas as bactérias. As concentrações de extrato restantes deram números consecutivamente mais baixos à medida que a concentração diminuía. Embora as maiores concentrações tenham sido eficazes contra bactérias, apresentaram valores elevados devido à cor do extrato que afetou a absorbância, em comparação com o controle positivo que apresentou valores menores em altas concentrações. $O$ controle positivo com as maiores concentrações de antibióticos apresentou valores de densidade óptica baixos, o que indica que os antibióticos foram eficazes contra as bactérias testadas. Com mais diluições do antibiótico, os valores de densidade óptica subsequentes dados aumentaram, à medida que o antibiótico se tornou menos eficaz nas bactérias. O controle negativo para todas as bactérias deu valores elevados que indicam que não houve inibição do crescimento devido a DMSO. Todos os meios de controle apresentaram valores de densidade óptica abaixo de 0,4 , o que confirma que o caldo utilizado não estava contaminado com bactérias. 
Uma análise de subcultura foi feita para poços contendo as três concentrações mais altas 5,0 mg / ml, 2,5 mg / ml e 1,25 mg / ml. O MIC para Enterobacter e E. coli foi de $5,0 \mathrm{mg} / \mathrm{ml}$, enquanto $2,5 \mathrm{mg} / \mathrm{ml}$ foi encontrado para ser MIC para Staphylococcus e Pseudomonas.

\section{Experiência de clareamento}

Para os trinta dentes manchados de chá, as leituras iniciais e finais do guia de clareamento ADA, luminosidade, croma e matiz foram feitas usando Vita EasyShade ${ }^{\circledR}$ Advance 4.0. Um teste $t$ de amostra pareada de duas caudas foi usado para comparar os valores das leituras antes e depois de conduzir o experimento. O guia de clareamento croma e ADA dos dentes escovados com o extrato mostrou diferença significativa, conforme mostrado na Tabela 5 .

Tabela 5: Dentes escovados com solução de extrato versus grupos de controle.

\begin{tabular}{|c|c|c|c|c|c|c|c|c|c|c|c|c|c|c|c|c|}
\hline \multirow[b]{2}{*}{ Grupos testados } & \multicolumn{4}{|c|}{ Leveza } & \multicolumn{4}{|c|}{ Matiz } & \multicolumn{4}{|c|}{ Croma } & \multicolumn{4}{|c|}{ Guia de branqueamento ADA } \\
\hline & $\begin{array}{c}\text { Antes } \\
\text { Média } \pm \\
\text { SD }\end{array}$ & $\begin{array}{c}\text { Após } \\
\text { Média } \pm \\
\text { SD }\end{array}$ & $\begin{array}{c}T- \\
\text { teste }\end{array}$ & $\begin{array}{c}P \\
\text { valor }\end{array}$ & $\begin{array}{c}\text { Antes } \\
\text { Média } \pm \\
\text { SD }\end{array}$ & $\begin{array}{c}\text { Após } \\
\text { Média } \pm \\
\text { SD }\end{array}$ & $\begin{array}{c}T- \\
\text { teste }\end{array}$ & $\begin{array}{c}P \\
\text { valor }\end{array}$ & $\begin{array}{c}\text { Antes } \\
\text { Média } \pm \\
\text { SD }\end{array}$ & $\begin{array}{c}\text { Após } \\
\text { Média } \pm \\
\text { SD }\end{array}$ & $\begin{array}{c}T- \\
\text { teste }\end{array}$ & $\begin{array}{c}P \\
\text { valor }\end{array}$ & $\begin{array}{c}\text { Antes } \\
\text { Média } \pm \\
\text { SD }\end{array}$ & $\begin{array}{c}\text { Após } \\
\text { Média } \pm \\
\text { SD }\end{array}$ & $\begin{array}{c}T- \\
\text { teste }\end{array}$ & $\begin{array}{c}P \\
\text { valor }\end{array}$ \\
\hline $\begin{array}{l}\text { Dentes escovados com solução de extrato ( } N \\
=15 \text { ) }\end{array}$ & $\begin{array}{c}1,25 \pm \\
0,76\end{array}$ & $\begin{array}{c}0,35 \pm \\
2,11\end{array}$ & 1,63 & $\begin{array}{c}> \\
0,05\end{array}$ & $\begin{array}{c}0,69 \pm \\
0,90\end{array}$ & $\begin{array}{c}1,37 \pm \\
3,23\end{array}$ & $-0,87$ & $\stackrel{>}{0,05}$ & $\begin{array}{c}-1,20 \pm \\
1,09\end{array}$ & $\begin{array}{c}3,02 \pm \\
2,94\end{array}$ & 2,36 & $<0,04$ & $\begin{array}{c}23,33 \pm \\
3,64\end{array}$ & $\begin{array}{c}14,88 \pm \\
7,71\end{array}$ & 4,26 & $<0,04$ \\
\hline $\begin{array}{l}\text { Dentes escovados com solução salina ( } N= \\
\text { 8) }\end{array}$ & $\begin{array}{c}0,70 \pm \\
0,94\end{array}$ & $\begin{array}{c}1,56 \pm \\
0,97\end{array}$ & $-1,79$ & $\begin{array}{c}> \\
0,05\end{array}$ & $\begin{array}{c}1,26 \pm \\
1,27\end{array}$ & $\begin{array}{c}3,78 \pm \\
2,79\end{array}$ & $-1,98$ & $\begin{array}{c}> \\
0,05\end{array}$ & $\begin{array}{c}-2,00 \pm \\
1,65\end{array}$ & $\begin{array}{c}-3,82 \pm \\
0,84\end{array}$ & 1,76 & $\begin{array}{c}> \\
0,05\end{array}$ & $\begin{array}{c}20,80 \pm \\
4,37\end{array}$ & $\begin{array}{c}17,80 \pm \\
6,42\end{array}$ & 0,98 & $\stackrel{>}{0,05}$ \\
\hline $\begin{array}{l}\text { Dentes armazenados apenas em solução } \\
\text { salina }(N=7)\end{array}$ & $\begin{array}{c}1,73 \pm \\
1,06\end{array}$ & $\begin{array}{c}1,63 \pm \\
0,93\end{array}$ & 1,00 & $\begin{array}{c}> \\
0,05\end{array}$ & $\begin{array}{c}2,07 \pm \\
1,27\end{array}$ & $\begin{array}{c}0,47 \pm \\
0,32\end{array}$ & 1,96 & $\begin{array}{c}> \\
0,05\end{array}$ & $\begin{array}{c}1,53 \pm \\
0,23\end{array}$ & $\begin{array}{c}-1,37 \pm \\
0,40\end{array}$ & $-1,39$ & $\begin{array}{c}> \\
0,05\end{array}$ & $\begin{array}{c}27,33 \pm \\
2,89\end{array}$ & $\begin{array}{c}25,00 \pm \\
1,37\end{array}$ & 3,50 & $\begin{array}{c}> \\
0,05\end{array}$ \\
\hline
\end{tabular}

"Diferença significativa em $P<0.05$

\section{teste de $\mathrm{pH}$}

$\mathrm{O}$ valor do $\mathrm{pH}$ foi determinado usando um medidor de $\mathrm{pH}$ digital, foi considerado ácido para todas as amostras testadas e tornou-se menos ácido à medida que o extrato se tornava mais diluído com solução salina. Os resultados detalhados são mostrados na Figura 2.

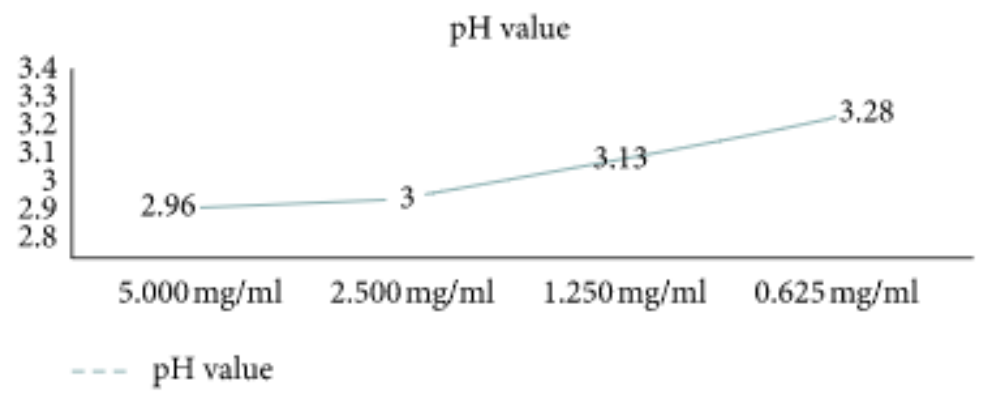

Figura 2: Resultados do teste de pH de diferentes concentrações do extrato.

\section{Discussão}


A placa bacteriana é a causa mais importante de inflamação gengival e cárie dentária. Este estudo mostra que a casca de Juglans regia tem efeito antimicrobiano e pode ser usada em práticas de higiene bucal para reduzir a carga bacteriana. 0 extrato etanólico de Juglans regia em altas concentrações provou inibir o crescimento de Staphylococcus , E. coli , Enterobacter e Pseudomonas, embora tenha pouco ou nenhum efeito em baixas concentrações. Um estudo anterior relatou que o extrato aquoso da casca de Juglans regia mostrou um efeito inibitório significativo contra Staphylococcus aureus, S. salivarius eS. sanguinis, mas não teve efeito sobre S. mutans . O extrato etanólico, no entanto, teve um efeito antimicrobiano significativo em todas as quatro bactérias [ 7 ]. Por outro lado, outro estudo concluiu que os extratos de acetona de Juglans regia são muito mais eficazes do que os extratos aquosos em amostras da flora microbiana salivar de pacientes com cárie dentária [ 8 ]. As propriedades antimicrobianas são atribuídas à presença de ciclobutanol e 1,3-dioxolano-4-metanol, 2, 2-dimetil em alta porcentagem no extrato metanólico da casca, conforme demonstrado em estudo conduzido por Ara et al. (2013) usando cromatografia gasosa-espectroscopia de massa [ 9] Além disso, as propriedades antimicrobianas também podem ser atribuídas à presença de compostos fenólicos, terpenóides, alcalóides, flavonóides e esteróides [ 9 ].

Juglan regia contém $\beta$ - sitosterol, ácido ascórbico, juglone, ácido fólico, regiolona, ácido gálico e quercetina-3-alfa-L-arabinosídeo [ 10]. As presentes descobertas revelaram que o $\mathrm{pH}$ de todas as diluições em série de 2 vezes começando com uma concentração de $5 \mathrm{mg} / \mathrm{ml}$ é ácido e, portanto, pode ser devido à presença desses compostos. Paradoxalmente, um estudo conduzido por Alkhawajah (1997) teve como objetivo testar o efeito de Juglans regia no $\mathrm{pH}$ da saliva in vivo, fornecendo um pedaço de Juglans regiaaos voluntários para escovar os dentes com ele. Em 40 minutos, o pH da saliva apresentou uma elevação onde atingiu um máximo de 7,55. Esse aumento do pH durou 3 horas. A mudança no $\mathrm{pH}$ ocorreu devido à estimulação da glândula salivar que amplificou a taxa de fluxo salivar, lavando e diluindo os ácidos [ 11 ].

A descoloração dos dentes pode ser categorizada em coloração intrínseca e extrínseca. A coloração intrínseca está relacionada à genética, ingestão de altos níveis de flúor e antibióticos durante a formação do dente, enquanto a coloração extrínseca é devida a fatores ambientais e compostos coloridos que são absorvidos pela película dentária adquirida na superfície do dente.

Ao mostrar uma diferença substancial no guia de clareamento de croma e ADA, o experimento de clareamento confirmou sua eficácia na remoção artificial de manchas extrínsecas. Isso pode ser explicado devido ao pH ácido da solução aliado à ação mecânica da escovação e do uso do pó abrasivo. Um estudo de Price et al. (2003) demonstraram o potencial de pastas contendo ácido para remover manchas brancas, amarelas e marrons do esmalte por ação de microabrasão [ 12, 13 ]. Com o uso intraoral do galho, a planta 
libera manchas escuras ao ser molhada pela saliva que mancha os tecidos moles, inclusive a gengiva. A percepção de dentes mais brancos após o uso da Juglans regiagalho pode ser experimentado devido ao contraste contra a gengiva escura. Mais estudos são necessários para explorar e identificar os mecanismos subjacentes de clareamento do extrato de Juglans regia como uma solução e usando o galho diretamente in vivo. Portanto, um ensaio clínico de acompanhamento de longo prazo com seres humanos é necessário para mostrar a diferença nos resultados entre o uso do galho diretamente na superfície do dente, que deve causar abrasividade, removendo assim as manchas, e o uso do extrato dissolvido em um solução que se verificou ser ácida.

\section{Conclusão}

Pensa-se que os extratos de Juglans regia têm potencial terapêutico, o que foi confirmado por este estudo devido ao notável efeito antimicrobiano da casca de Juglans regia contra Staphylococcus, Escherichia coli , Pseudomonas e Enterobacter, portanto, demonstrando a possibilidade de incorporá-lo em uma rotina de higiene dental para prevenir cáries e doenças periodontais.

Concluiu-se também que esta planta possui um pH ácido. Portanto, estudos adicionais são necessários para incorporar um tampão na solução para neutralizar a acidez de Juglans regia .

Finalmente, este estudo mostrou que Juglans regia tem uma capacidade potencial de clareamento dentário, que pode ser semelhante em conceito à microabrasão do esmalte. Mais estudos in vivo são necessários para ver se esta planta pode ser usada na cavidade oral sem causar sequelas prejudiciais aos dentes e suas estruturas de suporte, bem como comparar os métodos de aplicação e saber a possibilidade de incorporar a solução do extrato nos tipos de pasta de dente.

\section{Limitação do estudo}

Devido à falta de dentes extraídos necessários para o experimento de clareamento, os dentes não foram selecionados com base na cor que apresentavam antes da coloração artificial, o que pode ter afetado os resultados. Isso levou à seleção de um pequeno número de dentes caseiros e a um grupo de controle ainda menor. Um número maior de dentes teria produzido resultados mais confiáveis.

\section{THE AUTHORS DECLARE NO CONFLICTS OF INTEREST.}

\section{DECLARAÇÃO CCBY}

Este artigo é uma copia literal com adaptação para o português e mudança de autoria do artigo original "Riham Al-Rawi, Yusra Bashir, Aseel Mustafa, Mennatalla Omar, Noor 
AL-Rawi, Musab Saeed, Asmaa Uthman, Natheer H. Al-Rawi, "Teeth Whitening and Antibacterial Effects of Juglans regia Bark: A Preliminary Study", International Journal of

Dentistry, vol. 2021, Article ID 6685437, 9 pages, 2021. https://doi.org/10.1155/2021/6685437“

Esta copia com adaptação para o português e mudança de autoria não possui o endosso dos autores do artigo original e tão pouco do jornal onde foi publicado, apenas faz-se valer da licença CCBY cedida pelo jornal onde o artigo foi publicado.

Segue o link da licença https://creativecommons.org/licenses/by/4.0/deed.pt BR Segue o link do artigo original onde esta a licença https://www.hindawi.com/journals/ijd/2021/6685437/

\section{REFERÊNCIAS}

1. American Dental Association, ADA Policy-Definition of Oral Health, American Dental Association, Chicago, IL, EUA, 2017, http://www.ada.org/en/about-the-ada/adapositions-policies-and- declarações / ada-política-definição-de-saúde-bucal2014 .

2. JA Aas, BJ Paster, LN Stokes, I. Olsen e FE Dewhirst, "Definindo a flora bacteriana normal da cavidade oral," Journal of Clinical Microbiology, vol. 43, não. 11, pp. 5721-5732, 2005.Veja em: Site da Editora | Google Scholar

3. DA Devine, PD Marsh e J. Meade, "Modulation of host responses by oral commensal bactéria," Journal of Oral Microbiology , vol. 7, não. 1, Artigo ID 26941, 2015.Veja em: Site da Editora | Google Scholar

4. JW Wilson, MJ Schurr, CL LeBlanc, R. Ramamurthy, KL Buchanan e CA Nickerson, "Mechanisms of bacterial pathogenicity," Postgraduate Medical Journal , vol. 78, no 918, pp. 216-224, 2002.Veja em: Site da Editora | Google Scholar

5. P. Pollegioni, K. Woeste, F. Chiocchini et al., "Repensando a história da noz comum ( Juglans regia L.) na Europa: suas origens e interações humanas," PLoS One, vol. 12, não. 3, Artigo ID e0172541, 2017.Veja em: Site da Editora | Google Scholar

6. M. Yelne, P. Sharma e T. Dennis, Database on Medicinal Plants Used in Ayurveda, vol. 4, Conselho Central de Pesquisa em Ayurveda e Siddha, Chennai, Índia, 2002.

7. F. Zakavi, L. Golpasand Hagh, A. Daraeighadikolaei, A. Farajzadeh Sheikh, A. 
Daraeighadikolaei e Z. Leilavi Shooshtari, "Antibacterial effect of juglans regia latido contra bactérias patológicas orais", International Journal of Dentistry , vol. 2013, Artigo ID 854765, 5 páginas, 2013.Veja em: Site da Editora | Google Scholar

8. R. Deshpande, A. Kale, A. Ruikar et al., "Antimicrobial activity of different extract of juglans regia L. against oral microflora," International Journal of Pharmacy and Pharmaceutical Sciences , vol. 3, não. 2, pp. 200-201, 2011.Veja em: Google Scholar

9. I. Ara, MMA Shinwari, SA Rashed, e MA Bakir, "Avaliação das propriedades antimicrobianas de dois extratos diferentes de casca de árvore juglans regia e pesquisa de seus compostos usando espectro de massa de cromatohrafia gasosa," International Journal of Biology, vol. 5, não. 2, 2013.Veja em: Site da Editora | Google Scholar

10. S. Joshi, Medicinal Plants, Oxford 7 IBH, New Delhi, India, 2007.

11. AM Alkhawajah, "Estudos sobre a atividade antimicrobiana de juglans regia", The American Journal of Chinese Medicine , vol. 25, não. 2, pp. 175-180, 1997.Veja em: Site da Editora | Google Scholar

12. RBT Price, RW Loney, MG Doyle e MB Molding, "Uma avaliação de uma técnica para remover manchas de dentes usando microabrasão," The Journal of the American Dental Association , vol. 134, no. 8, pp. 1066-1071, 2003.

13. Garcia Arada, J. M. ., \& Perez, Z. C. . (2019). PHYTOTHERAPY IN DENTISTRY: SURVEY OF PRODUCTS OF PLANT ORIGIN FOR HEALTH ORAL. Brazilian Journal of Implantology and Health Sciences , 1(3), 35-40. 